\title{
A Game Theoretic Explanation of Economic Growth
}

\author{
Salman Sakir ${ }^{1}$ \\ ${ }^{1}$ Independent Researcher, P.O. Box 20581, 322 Rideau Street, Ottawa, ON K1N 1A3, Canada. \\ Correspondence: Salman Sakir, Independent Researcher, P.O. Box 20581, 322 Rideau Street, Ottawa, ON K1N 1A3, \\ Canada. Tel: 1-613-400-3280.
}

Received: May 6, 2015

Accepted: May 22, 2015

Available online: November 13, 2015

doi:10.11114/aef.v3i1.1194

URL: http://dx.doi.org/10.11114/aef.v3i1.1194

\begin{abstract}
This paper uses game theory to explain economic growth. It explores a possible reason outside the purview of conventional explanations of economic growth. The paper does not consider natural resources, human capital or capital endowment of a country in determining it being rich or poor. Alternatively, it uses game theory to capture the inconspicuous features of a society that may lead to it being prosperous or not.

It shows that cooperative games among the citizens lead a poor country to become rich over time while non-cooperative games can make a developed country become poor over time. Also, the paper provides real life explanations supporting this notion. Finally, the paper explores possible reasons for societies choosing cooperative and non-cooperative games.
\end{abstract}

Keywords: Game Theory, Cooperative Games, Non-cooperative games, Repeated games, Economic Growth.

JEL Classification: $\mathrm{C} 70, \mathrm{C} 71, \mathrm{C} 72, \mathrm{O} 40, \mathrm{O} 50$.

\section{Introduction}

Economic growth is a sought after goal in all countries, both developed and developing. While developing countries are trying to become prosperous, developed countries are trying to maintain high growth rates so as to maintain as well as improve the well-being of the people. It is observed that some countries have become highly developed even though they are not endowed with large populations or abundant natural resources. Again, some countries with significant natural resources and large populations have failed to develop. There are examples of countries with relatively high level of human capital, which have failed to economically prosper. It is possible that these societies differ in attributes that lead to them being prosperous or not.

The following section explores the existing ideas and theories on economic growth. It examines the significance of natural resource, human capital, etc. in explaining economic growth. Section 3 looks at using game theory to explain economic growth. Sections 4 and 5 broaden that research of using cooperative repeated games and non-cooperative repeated games to understand why countries may become prosperous or poorer over time. Section 6 ponders whether game theory could explain the emergence of institutions while Section 7 examines certain countries and tries to understand their economic performance using cooperative and non-cooperative games. Section 8 provides explanations of societies playing cooperative and non-cooperative games while section 9 offers some concluding remarks.

\section{What do existing theories say?}

There are different theories that explain economic growth. The economic prosperity of societies have been explained by the abundance or dearth of natural resources, human capital as well as institutions, especially economic institutions. Also, the importance of geography and culture has been explored in explaining economic growth of countries.

\subsection{Natural Resource and Economic Growth}

The influence of natural resource on economic growth has been researched. Studies have shown that natural resource may be a curse for economic growth while other studies have found natural resources to be beneficial. Again, additional studies have indicated that the use of natural resources may lead to a trade-off between short-run and long-run economic growth.

Sachs and Warner (1995) found a negative relationship exists between resource abundance and economic growth, even after controlling for additional variables like initial GDP, trade policy, investment rates, terms of trade volatility, inequality and the effectiveness of bureaucracy. They found that resource-poor economies outperformed resource-rich 
economies. The paper stated, "On average, countries with a high value of resource-based exports to GDP tend to have a lower growth rate." Again, Gylfason and Zoega (2001) found that natural resource is negatively related to economic growth. They stated that capital markets may not develop if there is excessive dependence on natural resources. However, the paper adds that resource rich countries can still have growth and increased welfare when institutional environment is created that stimulate savings and high-quality investment.

Behbudi, Mamipour and Karami (2010) found the existence of an inverse relationship between economic growth and natural resource abundance for petroleum exporting countries. They state, "In addition, this study provides evidence, though not particularly strong, of a negative relationship between human capital and natural resources. So this study shows that human capital serves as a transmission mechanism of the resource curse." However, there are studies which have indicated that "resource curse" is not necessarily true, an abundance of natural resources would not lead to lower economic growth. Torres, Afonso and Soares (2009) find a positive effect on capital efficiency arising from the closeness of geographically-concentrated natural resources that are adjusted for re-exportation, by hindering institutional quality. They state, "The positive impact by capital efficiency may reflect capital and technological intensity owing to the exploitation of those resources, in addition to economies of scale, since the geographic concentration allows the dilution of high fixed costs."

Chambers and Guo (2009) indicate that it is possible for an economy to achieve balanced growth while maintaining sustained economic growth and a non-deteriorating environment simultaneously. They state that there is a trade-off between short-term and long-term economic growth with the use of natural resources, and suggest that countries not depend significantly on natural resource based growth. Stijns (2000) finds that, "Natural resources may affect economic growth through both positive and negative channels". He finds that land is negatively correlated with the determinants of economic growth; however, this relationship is not applicable for minerals, coal, oil and natural gas. Also, the paper reveals that there is a positive relationship between school attendance and oil, gas and mineral reserves. Therefore, it is expected that a country with abundant oil, gas and mineral reserves would have high school attendance. An increase in high school attendance may indicate an increase in human capital, which may have a positive impact on economic growth.

\subsection{Population and Economic Growth}

Population can influence economic growth. The size of the population as well as the age of the population influence economic growth. When there is a large population, it may offer a potential labor force and a sizable consumer base. It is true that a sizable consumer base is not only dependent on population size but also on per capita income of the country. A large consumer base would lead to significant economic activity and boost economic growth. Again, when most of the population is of working age, a large population would lead to a large working population, which would help generate economic growth. Therefore, population size may be positively correlated with economic growth while a large working age population may augment economic growth. However, when most of the population is below working age and aged so that the dependent population is significant, it may lead to lower economic activity and growth. An increase in life expectancy and people working for a longer period of their lives could dampen the effects of an aging population on economic growth.

\subsection{Human Capital and Economic Growth}

It is argued that human capital influences economic growth. A high level of human capital may have a positive impact on the economic growth of a country. There are many papers that have explored the relationship between human capital and economic growth. Hanushek and Woessmann (2009) research the impact of schooling on economic growth. They state that, "The simple conclusion from the combined evidence is that differences in cognitive skills lead to economically significant differences in economic growth. Moreover, since the tests concentrate on the impact of schools, the evidence suggests that school policy can, if effective in raising cognitive skills, be an important force in economic development." Their argument that schooling may have a positive impact on economic growth only if it increases cognitive skills is quite convincing.

The quality of the labor force can influence economic growth. A healthy, educated and trained labor force would have high productivity, and create high value-added goods and services that would boost a country's growth. On the other hand, an unhealthy, illiterate, unskilled and semi-skilled labor force would have low productivity, and create low value-added goods and services, which may translate into low economic growth of a country. Hanushek and Kimko (2000) state that, "Labor-force quality has a consistent, stable, and strong relationship with economic growth." This indicates that the quality of the labor force has important influence on the economic growth of a country. Barro (2001) found a positive relationship between education and economic growth. His paper revealed that the quality of education and the quantity of education both positively influence economic growth; however, the quality of education plays a more important role. 
Barro (1991) found that, "Moreover, given the level of initial per capita GDP, the growth rate is substantially positively related to the starting amount of human capital." It mentions that a poor country can become a rich country only if it has high human capital per person. Also, the paper finds that political instability is inversely related to growth and investment. Castelló and Doménech (2001) find that education inequality may lead to lower income growth.

Some papers have found that the relationship between schooling and economic growth is quite weak. Bils and Klenow (2000) find that, "We find that the channel from schooling to growth is too weak to plausibly explain more than one-third of the observed relation between schooling and growth. This remains true even when we take into consideration the effect of schooling on technology adoption." Their paper show that the relationship between schooling and economic growth is not that strong.

\subsection{Institutions and Economic Growth}

It is argued that institutions can influence economic growth. The argument is that institutions can determine whether countries would become rich or poor. Acemoglu, Johnson and Robinson (2004) state, "differences in economic institutions are the fundamental cause of differences in economic development". Their paper state that the economic institutions in a society play a crucial role in determining economic outcomes. The paper explains that economic institutions like the structure of property rights, and the presence and perfection of markets play an important role as they determine the structure of economic incentives in society. The paper mentions, "Societies with economic institutions that facilitate and encourage factor accumulation, innovation and the efficient allocation of resources will prosper" while adding that institutions are endogenous to a society. The paper also discusses the role of geography and culture in influencing economic growth; however, it emphasizes on institutions, especially, economic institutions, in explaining economic growth.

The explanation of economic growth using institutions and, particularly, economic institutions could explain the reason for economic success in capitalist countries. As Acemoglu, Johnson and Robinson (2004) discuss, economic institutions could explain the economic outcomes of South Korea and North Korea. South Korea implemented a market-oriented economy and became economically prosperous while North Korea being a communist country, failed to achieve economic success.

\subsection{Geography, Culture and Religion, and Economic Growth}

Some have argued that geography plays an important role in economic growth. Gallup, Sachs and Mellinger (1998) state that location and climate have significant impact on income levels and income growth. They add that geography can affect economic policy, and regions that have high population density and rapid population growth are not conducive to modern economic growth. The paper mentions that populations that are far from the coast and face large transportation costs for international trade, and populations in tropical regions of high disease burden are especially vulnerable to this problem. However, there are regions like Singapore and Hong Kong that are tropical regions, have significant population density and relatively large population relative to their geographical size, and still have experienced impressive economic growth. Botswana is a landlocked country and has subtropical desert climate; however, it has grown continuously for several decades. The thesis proposed by Gallup, Sachs and Mellinger (1998) is not necessarily true as there are countries which have grown substantially inspite of being landlocked, tropical, have large populations and high population density. Again, studies have been conducted to understand the influence of culture and religion on economic growth.

\section{Using Game Theory to explain Economic Growth}

A different approach is taken in explaining economic growth in this paper. It argues that the inconspicuous attributes of the citizens of a country may determine and explain economic growth. These inconspicuous attributes of the citizens determine the actions that they take. These actions can be captured as strategies in game theory. The strategies chosen in these games can be used to explain the economic growth trajectories of countries. When a cooperative game is played, it leads to a very different economic outcome compared to a game of non-cooperation. This is irrespective of the level of natural resources and human capital that a country possesses. Repeated games accentuate the effects of these strategies on the economic growth of a society.

\section{Games of Cooperation and Repeated Games}

Table 1 shows a hypothetical country with two citizens, A and B. The country is at an initial stage of development so that the pay-offs to each player is low. The pay-offs of playing various strategies are shown in Table 1. The two players play a cooperative game and end up with a payoff of $(1,1)$. After playing the first round of cooperative games, the 'country' is richer with each citizen gaining one unit of the country's gains. Then, the players again play the game as shown in Table 2. They play a cooperative game and end up with an outcome of $(2,2)$. Each of the players gain two units and the 'country' becomes richer. The two players keep on playing cooperative games and their payoffs increase. 
Table 1. Two players playing a round of cooperative games

\begin{tabular}{lcc}
\hline & Player A & Player B \\
\hline Player A & $(1,1)$ & $(0,2)$ \\
Player B & $(2,0)$ & $(-1,-1)$ \\
\hline
\end{tabular}

Table 2. Two players playing a second round of repeated cooperative games

\begin{tabular}{lcc}
\hline & Player A & Player B \\
\hline Player A & $(2,2)$ & $(0,4)$ \\
Player B & $(4,0)$ & $(-2,-2)$ \\
\hline
\end{tabular}

In the ninth round, the players continue playing a cooperative game so that they end up with an outcome of $(9,9)$. Table 3 demonstrates that the players are significantly richer while the 'country' is substantially well-off. As shown in Table 4, the players each gain ten units in the tenth round of cooperative games. The payoffs for the players have increased by playing repeated cooperative games and, consequently, the 'country' is far richer than before. Even though the country started at a low stage of development, cooperative games played by the two players have made it prosperous over time.

Table 3. Two players playing the ninth round of repeated cooperative games

\begin{tabular}{lcc}
\hline & Player A & Player B \\
\hline Player A & $(9,9)$ & $(0,18)$ \\
Player B & $(18,0)$ & $(-9,-9)$ \\
\hline
\end{tabular}

Table 4. Two players playing the tenth round of repeated cooperative games

\begin{tabular}{lcc}
\hline & Player A & Player B \\
\hline Player A & $(10,10)$ & $(0,20)$ \\
Player B & $(20,0)$ & $(-10,-10)$ \\
\hline
\end{tabular}

\section{Games of Non-cooperation and Repeated games}

Table 5 shows a hypothetical country with two citizens, C and D. Let's assume that the country is a very developed country. When the two players play a cooperative game, their pay-offs are quite high, $(10,10)$, as the country is very developed and the citizens, $\mathrm{C}$ and $\mathrm{D}$, are also rich. However, $\mathrm{C}$ and $\mathrm{D}$ play a non-cooperative game that lead to the pay-off $(-1,-1)$. They both end up losing one unit each and the country is slightly poorer than before.

Table 5. Two players playing a round of non-cooperative games

\begin{tabular}{lcc}
\hline & Player C & Player D \\
\hline Player C & $(10,10)$ & $(0,20)$ \\
Player D & $(20,0)$ & $(-1,-1)$ \\
\hline
\end{tabular}

After the first round of the game, the players play a second round of non-cooperative games as shown in Table 6 . This time, their pay-offs are $(-2,-2)$. Each of the players loose two units and the 'country' grows poorer. The non-cooperative games are played repeatedly as shown in Tables 7 and 8. In each round, the players loose more and the 'country' becomes poorer. In the tenth round, the players continue to play a non-cooperative game and each loose ten units and the 'country' becomes a poor, least developed country. Even though the 'country' started off as a rich country, the non-cooperative games played by its 'citizens' led to it become a poor country.

Table 6. Two players playing a second round of repeated non-cooperative games

\begin{tabular}{lcc}
\hline & Player C & Player D \\
\hline Player C & $(9,9)$ & $(0,18)$ \\
Player D & $(18,0)$ & $(-2,-2))$ \\
\hline
\end{tabular}

Table 7. Two players playing the third round of repeated non-cooperative games

\begin{tabular}{lcc} 
& Player C & Player D \\
\hline Player C & $(8,8)$ & $(0,16)$ \\
Player D & $(16,0)$ & $(-3,-3))$ \\
\hline
\end{tabular}


Table 8. Two players playing the tenth round of repeated non-cooperative games

\begin{tabular}{lcc} 
& Player C & Player D \\
\hline Player C & $(1,1)$ & $(0,2)$ \\
Player D & $(2,0)$ & $(-10,-10)$ \\
\hline
\end{tabular}

6. Could Game Theory explain the Emergence of Institutions?

Game theory may be used to explain the emergence of institutions, including economic institutions that Acemoglu, Johnson and Robinson (2004) mention are crucial to economic growth. Repeated games of cooperation among the citizens of a country would lead to the creation of strong institutions, including strong economic institutions, which would foster growth and development in the country. Again, repeated games of non-cooperation among the citizens of a country may lead to the emergence of weak institutions, including weak economic institutions. The weak economic institutions could explain the resultant low economic progress of the country. Therefore, repeated games of cooperation and non-cooperation could explain the emergence of strong institutions and weak institutions respectively, and the consequent economic outcomes of societies.

\section{Real Life Explanations}

There are countries which have played repeated cooperative games and developed quickly. Singapore is a country that has developed significantly with almost no natural resource. With a population that is racially diverse, it has been able to build a very prosperous country with an extremely high standard of living. The people of Singapore played repeated cooperative games that led to the country become rich over time. From a very low economic base, the people of Singapore cooperated to build the country into a prosperous one.

The same phenomenon is observed in the case of other Asian Tigers. South Korea has developed very rapidly in the last several decades. Investment-friendly and export-friendly policies led to rapid growth of the country that has limited natural resources. Repeated cooperative games played by the citizens and various stakeholders resulted in significant progress of the country.

The United States ascent and continuation as an economic superpower can also be characterized as a result of repeated cooperative games. With citizens of diverse backgrounds, the United States played repeated cooperative games. The various stakeholders like the government, consumers, businesses and exporters played repeated cooperative games that led to continued innovation and economic growth in the country leading to it become a superpower and maintain its status as a superpower. Repeated cooperative games played by the various stakeholders led the United States to become a leader in technology, commerce, etc.

China's ascent to the position of second-largest economy in the world can also be characterized as repeated cooperative games. The different stakeholders like workers, businesses, government, exporters, etc. played repeated cooperative games for the last few decades leading to high economic growth in the country.

Botswana is an example of a resource rich country that has recorded impressive growth. Built on diamond mining, the country has grown at high rates for several decades. Again, repeated cooperative games played by the various stakeholders like government, mining industry, workers, businesses, etc. led to political stability, financial stability and less corruption resulting in impressive growth of the country's economy.

There are examples of repeated non-cooperative games that have led a country or society to become poor over time. Countries that have been embroiled in civil wars are examples of countries where the citizens played repeated non-cooperative games. The Democratic Republic of the Congo is an example where non-cooperative games were played leading to unrest and civil wars. Even though the country is very rich in natural resources, it has been unable to develop and was embroiled in civil war for a long time. A game of repeated non-cooperation among the citizens led to instability and the country becoming poorer over time.

Sri Lanka is a country with a high literacy rate. A high literacy rate of the population would indicate a high level of human capital. Even though it had a high literacy rate, Sri Lanka did not experience significant economic growth due to the existence of prolonged civil war in the country. The civil war which emerged according to ethnic lines resulted in destruction of property, suffering and low economic growth. Repeated non-cooperative games between the two ethnic groups resulted in the country experiencing low economic growth although it had a highly literate population.

\section{Possible Explanation of Cooperative and Non-Cooperative Games}

There are possible explanations for citizens playing cooperative and non-cooperative games. A society may play cooperative games when the citizens have a common goal to achieve, which may be higher economic growth, developed society and better governance. It is important to realize that citizens would play cooperative games when the benefits of economic growth and better governance are shared and enjoyed by all or, atleast, the majority of the citizens. 
The benefits don't necessarily have to be enjoyed and shared equally but, has to positively affect the mass of the population. When the benefits are widely enjoyed, it does not guarantee that the citizens would necessarily play cooperative games but, it is fair to say that it certainly helps in encouraging the citizens to play cooperative games.

Extreme tension along racial, religious or territorial lines may lead citizens to play non-cooperative games, where they are willing to accept a loss as long as the other group loses. However, the same phenomenon may be observed within a particular group if an extreme form of jealousy exists within members of the group. Sharp divisions along political lines in a homogeneous society may lead to citizens playing non-cooperative games, which may lead to governance failure and destruction of the society and economy. Again, when people feel that they are not enjoying the success of the country whether it is economic or social, they may play non-cooperative games. This may be especially true when the 'successful' are perceived by the mass of the population to have gained their financial or social standing through unscrupulous means. Therefore, limited sharing of economic and social success in a society may lead to the appearance of non-cooperative games among its population.

\section{Conclusion}

Economic growth has been explained by the absence or existence of natural resource. Some papers have argued that high level of human capital may lead to economic growth. Also, others have suggested that institutions, particularly economic institutions, play a role in increasing economic growth. Again, papers have explained economic growth using location and climate while others have pondered the influence of religion and culture on economic growth. However, there are examples of landlocked countries and tropical countries which have grown inspite of these perceived limitations. This paper explains economic growth using game theory by considering the behavioral traits of the citizens in a society.

The play of cooperative games or non-cooperative games in a society can dictate the economic outcome of a society. When a cooperative game is played repeatedly, a society could become richer over time. Again, when a non-cooperative game is played repeatedly, a society could become poorer over time. Therefore, the strategies of the citizens could dictate the economic prosperity of a country. Certain conditions, like limited sharing of economic and social success in a society, may lead to the emergence of non-cooperative behavior among its citizens. On the other hand, policies that are deemed beneficial by the mass of the population may encourage the populace to behave in cooperative ways. The play of cooperative and non-cooperative games can dictate the economic and social success of a society.

\section{References}

Acemoglu, D., Simon, J., \& James, R. (2004). Institutions as the Fundamental Cause of Long-Run Growth. NBER Working Paper, 10481, May. http://www.nber.org/papers/w10481.pdf. http://dx.doi.org/10.3386/w10481

Barro, R. J. (1991). Economic Growth in a Cross Section of Countries. Quarterly Journal of Economics, 106(2), 407-443. http://www.econ.nyu.edu/user/debraj/Courses/Readings/BarroGrowth.pdf. http://dx.doi.org/10.2307/2937943

Barro, R. J. (2001). Human Capital and Growth. AEA Papers and Proceedings, 91(2), 12-17. http://www4.fe.uc.pt/mapsd/barro_aer01.pdf.

Barro, R. J., \& Rachel, M. M. (2003). Religion and Economic Growth Across Countries. American Sociological Review, 68(5), 760-781, October. http://www.ppge.ufrgs.br/giacomo/arquivos/eco02237/barro-mccleary-2003-2.pdf.

Barro, R. J., \& Rachel, M. M. (2006). Religion and Economy. Journal of Economic Perspectives, 20(2), 49-72, Spring. http://isites.harvard.edu/fs/docs/icb.topic96263.files/Religion_and_Economy.pdf.

Behbudi, D., Siab, M., \& Azhdar, K. (2010). Natural Resource Abundance, Human Capital and Economic Growth in the Petroleum Exporting Countries. Journal of Economic Development, 35(3), 81-102. http://www.jed.or.kr/full-text/35-3/4.pdf.

Bils, M., \& Peter, J. K. (2000). Does Schooling Cause Growth? American Economic Review, 90(5), 1160-1183. http://klenow.com/BKHK.pdf.

Castelló, A., \& Rafael, D. (2001). Human Capital Inequality and Economic Growth: Some New Evidence. Universitat Jaume I, Castellón and Universidad de Valencia, July. http://iei.uv.es/ rdomenec/human/h_ineq.pdf.

Chambers, D., \& Jang-Ting, G. (2009). Natural Resources and Economic Growth: Some Theory and Evidence. Annals of Economics and Finance, 10(2), 367-389. http://down.aefweb.net/AefArticles/aef100207.pdf.

Cohen, D., \& Marcelo, S. (2007). Growth and Human Capital: Good data, good results. Journal of Economic Growth. 12(1), 51-76. http://www.parisschoolofeconomics.eu/docs/cohen-daniel/cohen-soto-2007.pdf.

DalBó, P., \& Guillaume, R. F. (2011). The Evolution of Cooperation in Infinitely Repeated Games: Experimental 
Evidence. American Economic Review, 101(1), 411-429.

http://www.econ.brown.edu/fac/Pedro_Dal_Bo/evolutionofcooperation.pdf.

Fudenberg, D., \& Eric, M. (1990). Evolution and Cooperation in Noisy Repeated Games. American Economic Review, 80(2), 274-279. http://www.dklevine.com/archive/refs4546.pdf.

Gallup, J. L., Jeffrey, D. S., \& Andrew, D. M. (1998). Geography and Economic Development. NBER Working Paper 6849, December. http://www.nber.org/papers/w6849.pdf.

Guiso, L., Paola, S., \& Luigi, Z. (2006). Does Culture Affect Economic Outcomes? NBER Working Paper 11999, January. http://www.nber.org/papers/w11999.pdf.

Gylfason, T., \& Gylfi, Z. (2001). Natural Resources and Economic Growth: The Role of Investment. Economic Policy Research Unit, Institute of Economics, University of Copenhagen, January. http://www.econ.ku.dk/epru/files/wp/WEB-blaa-2001-02.pdf.

Gylfason, T. (2001). Natural Resources and Economic Growth: What is the connection? CESifo Working Paper, 530, August. https://ideas.repec.org/p/ces/ceswps/_530.html.

Hanushek, E. A. \& Dennis, D. K. (2000). Schooling, Labor-force quality, and the Growth of Nations. American Economic Review, 90(5), 1184-1208.

http://www2.econ.iastate.edu/classes/econ520/Huffman/documents/SchoolingLaborForceQualityandtheGrowthofN ations.pdf.

Hanushek, E. A., \& Ludger, W. (2008). The Role of Cognitive Skills in Economic Development. Journal of Economic Literature, 46(3), 607-668, September.

http://hanushek.stanford.edu/sites/default/files/publications/Hanushek\%2BWoessmann\%202008\%20JEL\%2046(3) .pdf.

Hanushek, E. A., \& Ludger, W. (2009). Do Better Schools Lead to More Growth? Cognitive Skills, Economic Outcomes and Causation. NBER Working Paper, 14633, January. http://www.nber.org/papers/w14633.

Hanushek, E. A., \& Ludger, W. (2010). Education and Economic Growth. International Encyclopedia of Education, 2, 242-252.

http://hanushek.stanford.edu/sites/default/files/publications/Hanushek\%2BWoessmann\%202010\%20IntEncEduc\% 202.pdf.

Hausmann, R., Lant, P., \& Dani, R. (2004). Growth Accelerations. NBER Working Paper, 10566, June. http://www.nber.org/papers/w10566.pdf.

Krueger, A. B., \& Mikael, L. (2001). Education for Growth: Why and for Whom? Journal of Economic Literature, 39(4), 1101-1136, December. http://www00.unibg.it/dati/corsi/91015/49249-jel\%202000_kruegerlindahl.pdf.

Leong, C. K. (2008). Capitalism and Economic Growth: A Game-Theoretic Perspective. MPRA Paper, 10472, September. http://mpra.ub.uni-muenchen.de/10472/1/femes08_ckleong.pdf.

Mankiw, N. G., David, R., \& David, N. W. (1992). A Contribution to the Empirics of Economic Growth. Quarterly Journal of Economics, 107(2), 407-437. http://eml.berkeley.edu/ dromer/papers/MRW_QJE1992.pdf.

Maskin, E. (2010). Culture, Cooperation and Repeated Games. Institute for Advanced Study, Prepared for a volume of papers from the Samuel P. Huntington Symposium, Higher School of Economics, Moscow, October. http://scholar.harvard.edu/files/maskin/files/culture_cooperation_and_repeated_games.pdf.

Roys, N., \& Ananth, S. (2014). On the Origins and Causes of Economic Growth. Department of Economics, University of Wisconsin-Madison, November.

http://www.sv.uio.no/esop/english/research/news-and-events/events/guest-lectures-seminars/esop-seminar/dokume nter/ananth-on-the-origin.pdf.

Sachs, J. D., \& Andrew, M. W. (1995). Natural Resource Abundance and Economic Growth. NBER Working Paper 5398, December. http://www.nber.org/papers/w5398.pdf.

Stijns, J. C. (2000). Natural Resource Abundance and Economic Growth Revisited. Department of Economics, University of California at Berkeley, November. http://citeseerx.ist.psu.edu/viewdoc/download?doi=10.1.1.321.8113\&rep=rep1\&type=pdf.

Toman, M. (2003). The Roles of the Environment and Natural Resources in Economic Grwoth Analysis. Resources for the Future, Discussion Paper 02-71, May. http://www.rff.org/documents/rff-dp-02-71.pdf.

Torres, N., Óscar, A., \& Isabel, S. (2009). Natural Resources, Economic Growth and Institutions-A Panel Approach. 
FEP Working Papers 338, October.

http://www.fep.up.pt/investigacao/workingpapers/09.10.20_wp338.pdf.

Williamson, C. R., \& Rachel, L. M. (2011). Economic Freedom, Culture and Growth. Public Choice, Springer, 148(3), 313-335. http://www.nyudri.org/wp-content/uploads/2011/10/driwp33.pdf.

Yamamoto, Y. (2012). Individual Learning and Cooperation in Noisy Repeated Games. PIER Working Paper, 1244, November. https://economics.sas.upenn.edu/sites/economics.sas.upenn.edu/files/12-044.pdf.

\section{(cc) $\mathrm{EY}^{\mathrm{X}}$}

This work is licensed under a Creative Commons Attribution 3.0 License. 